\title{
TiN/NbN Nanoscale Multilayer Coatings Deposited by High Power Impulse Magnetron Sputtering to Protect Medical-Grade CoCrMo Alloys
}

\author{
Arunprabhu Arunachalam Sugumaran ${ }^{1, *(D)}$, Yashodhan Purandare ${ }^{1}$, Krishnanand Shukla $^{1}$, Imran Khan ${ }^{2}$, \\ Arutiun Ehiasarian ${ }^{1}$ and Papken Hovsepian ${ }^{1}$ \\ 1 National HIPIMS Technology Centre, Materials and Engineering Research Institute, \\ Sheffield Hallam University, Howard Street, Harmer Building, Sheffield S1 1WB, UK; \\ Y.Purandare@shu.ac.uk (Y.P.); Krishnanand.Shukla@student.shu.ac.uk (K.S.); A.Ehiasarian@shu.ac.uk (A.E.); \\ P.Hovsepian@shu.ac.uk (P.H.) \\ 2 Zimmer-Biomet UK Limited, Dorcan Industrial Estate, Swindon SN3 5HY, UK; \\ Imran.Khan@zimmerbiomet.com \\ * Correspondence: A.Arunachalamsugumaran@shu.ac.uk; Tel.: +44-(0)114-225-6322; Fax: +44-(0)114-225-3500
}

\section{check for}

updates

Citation: Sugumaran, A.A.; Purandare, Y.; Shukla, K.; Khan, I.; Ehiasarian, A.; Hovsepian, P. TiN/NbN Nanoscale Multilayer Coatings Deposited by High Power Impulse Magnetron Sputtering to Protect Medical-Grade CoCrMo Alloys. Coatings 2021, 11, 867. https://doi.org/10.3390/ coatings11070867

Academic Editor: Joerg Vetter

Received: 28 June 2021

Accepted: 16 July 2021

Published: 20 July 2021

Publisher's Note: MDPI stays neutral with regard to jurisdictional claims in published maps and institutional affiliations.

Copyright: (c) 2021 by the authors. Licensee MDPI, Basel, Switzerland. This article is an open access article distributed under the terms and conditions of the Creative Commons Attribution (CC BY) license (https:// creativecommons.org/licenses/by/ $4.0 /)$.

\begin{abstract}
This study describes the performance of nanoscale multilayer TiN/NbN coatings deposited on CoCrMo medical-grade alloys by utilising novel mixed high power impulse magnetron sputtering (HIPIMS) and direct current unbalanced magnetron sputtering (UBM) technique in an industrial size vacuum coater. Scanning electron microscopy analysis showed that these coatings were extremely dense without any intercolumnar voids. The coating exhibited high hardness of $28 \mathrm{GPa}$, as well as low friction and wear coefficient of 0.7 and $1.4 \times 10^{-14} \mathrm{~m}^{3} \cdot \mathrm{N}^{-1} \cdot \mathrm{m}^{-1}$, respectively, as compared to the bare material. Scratch tests revealed superior coating to substrate adhesion due to the HIPIMS etching prior to coating deposition. Energy-dispersive X-ray analysis of the wear debris generated during the impact test together with focused ion beam cross-section analysis in different locations of the impact crater revealed the coating failure mechanism and further confirmed the excellent coating to substrate bonding strength. Potentiodynamic polarisation tests in $\mathrm{NaCl}$ and Hank's solutions revealed the clear passivation behaviour, several orders of magnitude lower corrosion currents, and high pitting potentials of the coating, which guarantee excellent protection to the base alloy in such aggressive environments. Inductively coupled plasma mass spectrometry analysis of Hank's solution containing corrosion debris of the coated sample revealed that the leaching of harmful metal ions from the base material was reduced to below the detection limit of the technique, thus demonstrating the high barrier properties of the coating.
\end{abstract}

Keywords: high power impulse magnetron sputtering (HIPIMS); CoCrMo alloy; TiN/NbN multilayer coating; wear resistance; fatigue resistance; fracture toughness; corrosion-resistant

\section{Introduction}

CoCrMo alloys have been widely used for biomedical applications such as knee and hip replacement joints due to their excellent biocompatibility, mechanical, and corrosion properties. However, the major drawback of using these alloys is the release of toxic, carcinogenic $\mathrm{Cr}$ and $\mathrm{Co}$ elements due to tribocorrosion [1-3]. It has been reported that the performance of these implants can be enhanced by depositing suitable monolithic or multilayer structured protective coatings. The merits and demerits of TiN coating deposited on $\mathrm{CoCr}$ alloys by a variety of techniques have been well documented by many authors [4-6]. Neumann et al. discussed the potential application of arc-deposited monolithically grown binary nitride based on biocompatible metals such as TiNbN coating for SS implants [7]. Hamelynck et al. found a huge reduction of $\mathrm{Cr}$ ion release from $\mathrm{CoCrMo}$ hip component due to TiNbN coating deposited by physical vapour deposition [8]. Recently, 
the reduction of $\mathrm{Co}, \mathrm{Cr}$, and $\mathrm{Mo}$ ion release from $\mathrm{CoCrMo}$ knee implant has been achieved by depositing $\mathrm{CrN} / \mathrm{NbN}$ nanoscale multilayer structured coatings by high power impulse magnetron sputtering (HIPIMS) [9]. To the best of the authors' knowledge, the literature available on the surface engineering of CoCrMo alloys by HIPIMS is scarce.

HIPIMS is a novel pulse power magnetron sputtering technique upscaled for the first time at Sheffield Hallam University, UK, by Prof. A. P. Ehiasarian, that produces highly ionised plasma consisting of more metal ions than metal neutrals unlike conventional direct current unbalanced magnetron sputtering, henceforth UBM [10]. The high flux ion bombardment increases the ad-atom mobility on the surface of the growing coating which eventually leads to smooth coatings with extremely dense microstructure [11]. The highly dense microstructure is one of the prerequisites for many performance enhancements such as corrosion and wear resistance. It has been reported that the surface pre-treatment using metal ion rich HIPIMS plasma considerably increased the adhesion between coating and substrate as compared to pre-treatments in Ar glow discharge and cathodic vacuum arc processes $[12,13]$. It has been demonstrated that $\mathrm{Nb}$ ion pre-treatment and deposition of $\mathrm{Nb}$ base layer using HIPIMS discharge prior to coating deposition significantly enhances adhesion and corrosion resistance of $\mathrm{CrN} / \mathrm{NbN}$ multilayer coatings [14].

The aim of this work was to widen the scope of specialised protective coatings for medical-grade CoCrMo alloys by development and detailed investigation of the mechanical, tribological, and corrosion behaviour of TiN/ $\mathrm{NbN}$ multilayer coatings utilising nanoscale multilayer/superlattice structure. Combined HIPIMS/UBM technique was used for the deposition to take advantage of highly ionised metal rich HIPIMS plasma without compromising the deposition rate [15].

\section{Materials and Methods}

\subsection{TiN/NbN Nanoscale Multilayer Coating Design Strategy and Deposition Procedure}

Adoption of a correct coating design strategy to meet the specific demands of each particular application is of paramount importance [16]. This is particularly true for the case of coatings dedicated to serve in the delicate environment of the human body. The first step in such design strategy is the material selection process. TiN/ $\mathrm{NbN}$ is chosen on the basis of metals, which show the highest biocompatibility in the human body. The next design step is the coating architecture selection. The nanoscale multilayer/superlattice structure is one of the most advantageous structures providing enhanced material properties such as super hardness, high fracture toughness, and impact load resistance, as well as excellent barrier properties and corrosion resistance in particular [17]. Finally, selection of a proper coating deposition technique must be considered as a critical step for the overall performance of the coating as this defines the adhesion strength and the coating density which determines the barrier properties. To produce the nanoscale/superlattice structured TiN/NbN coating, we selected the novel HIPIMS technology to guarantee reliable performance in the demanding medical implant application.

TiN/NbN nanoscale multilayer coatings have been produced in an industrial-size, four-cathode, HTC 1000-4 coating system (Hauzer Techno Coating B.V., Venlo, the Netherlands) enabled with HIPIMS technology at Sheffield Hallam University, UK. The coatings were deposited on mirror-polished $\left(R_{\mathrm{a}}\right.$ : in the range of $15-20 \mathrm{~nm}, 1 \mu \mathrm{m}$ diamond paste finish) $\mathrm{CoCr}$ coupons and $\mathrm{Si}(001)$ wafers. The mirror-polished substrates were cleaned in an automated industrial size ultrasonic cleaning line comprising of number of tanks filled with alkaline cleaning water solutions and de-ionised (DI) water for rinsing. Subsequently, the substrates were subjected to drying at a high temperature of $95{ }^{\circ} \mathrm{C}$ in a vacuum dryer. Prior to the coating deposition, the substrates were bombarded by a mixture of $\mathrm{Nb}^{+}$and $\mathrm{Ar}^{+}$ions generated by HIPIMS discharge sustained on a Nb target in Ar atmosphere [13]. The ion mixture was accelerated towards the substrate by applying a high bias voltage of about $-1000 \mathrm{~V}$ using a dedicated HIPIMS compatible bias power supply [18] connected to a specialised turntable allowing threefold rotation of the samples. During this ion etching procedure, the substrates were sputter cleaned (removal of oxides and other contaminants) 
and a shallow $\mathrm{Nb}^{+}$metal ion implanted zone was also produced in the substrate. This ion implanted zone exhibits a well-defined crystal structure which promotes the localised epitaxial growth of the coating, leading to excellent coating to substrate adhesion [12]. The coating deposition was carried out in a reactive $\mathrm{Ar}+\mathrm{N}_{2}$ atmosphere at $400^{\circ} \mathrm{C}$. The coatings were deposited on monolithically grown $\mathrm{NbN}$ base layer. Two targets (one $\mathrm{Nb}$ and one $\mathrm{Ti}$ ) were operated in HIPIMS mode and two targets (one $\mathrm{Nb}$ and one Ti) were operated in UBM mode during the coating deposition process.

\subsection{Characterisation Techniques}

A variety of analytical techniques were used to characterise the coatings. Adhesion strength of the coating was evaluated by scratch (ISO20502) and Rockwell C indentation (ISO26443) tests. CSM Instruments SA Revetest scratch tester (CSM Instruments SA, Anton Paar, Graz, Austria) was used to produce scratches by moving the sample under the diamond indenter where the applied normal force was $80 \mathrm{~N}$. An optical microscope (Olympus, Tokyo, Japan) was used to analyse the Rockwell C indents and to determine the critical load, $\mathrm{L}_{\mathrm{C} 2}$, during the scratch test.

An Empyrean X-ray diffractometer (Malvern PANalyitcal Empyrean, Malvern, UK) with Co source was used to define the bilayer thickness of the TiN/NbN multilayer coating. The BB $(\theta-\theta)$ geometry was used with an angular step size of $0.003^{\circ}$ between $2 \theta$ values of $2^{\circ}$ and $10^{\circ}$ for determining the bilayer thickness. The bilayer thickness $(\Lambda)$ in the low angle region was calculated directly from the standard Bragg equation:

$$
\Lambda=\frac{\mathrm{n} \lambda}{2 \sin \theta}
$$

where $\theta$ is the Bragg angle, $\lambda$ is wavelength of incident ray, and $n$ is the order of reflection.

The coating microstructure was examined by scanning electron microscopy using an FEI Nova-NanoSEM 200 instrument. The hardness and Young's modulus were measured in a Nano Indentation Tester (CSM Instruments SA, Anton Paar, Graz, Austria) using Oliver-Pharr method under an applied normal a load of $10 \mathrm{mN}$. The nanohardness value was averaged after producing 20 indentations. Knoop hardness was measured using a Mitotoyo micro hardness tester (load of $0.25 \mathrm{~N}$ ).

A pin on disc tribometer (CSM Instruments SA, Anton Paar, Graz, Austria) was used to measure the dry sliding friction coefficient $(\mu)$ and wear coefficient $\left(K_{C}\right)$ of the coatings. The tests were carried out in ambient environment using $6 \mathrm{~mm}$ diameter Alumina ball under $5 \mathrm{~N}$ normal load and sliding speed of $10 \mathrm{~cm} / \mathrm{s}$. To aid the coefficient of wear calculation, we used a Dektak-150 diamond stylus profilometer to determine the wear volume loss by profiling the wear track.

A CemeCon impact load tester (CemeCon, Horseheads, NY, USA) was used to evaluate the impact load fatigue behaviour of the $\mathrm{TiN} / \mathrm{NbN}$ coated specimens under dynamic loading conditions. The counterpart was a tungsten carbide (WC) ball of $6 \mathrm{~mm}$ diameter. A fixed normal load of $500 \mathrm{~N}$ at a frequency of $50 \mathrm{~Hz}$ was applied during all the tests. Impact craters were profiled using a profilometer (Dektak 150, Bruker, Billerica, MA, USA) with a resolution of $33 \mathrm{~nm}$. The impact crater of the TiN/NbN superlattice coating was further examined by producing focused ion beam cross-sections (FIB-CS) at different locations. The composition of the wear debris accumulated in the crater was defined by energy-dispersive X-ray (EDX) elemental mapping.

The fracture toughness of the coating was investigated by producing indentations at normal load of 500 N. A STRUERS microhardness tester equipped with a Vickers indenter (pyramidal shape) was used to produce the indentations. This excessively high penetration load of $\mathrm{P}=500 \mathrm{~N}$ was applied irrespective of the TiN/ $\mathrm{NbN}$ coating thickness in order to 
promote crack initiation. The fracture toughness values of all specimens were calculated using the formula proposed in [19]:

$$
\mathrm{K}_{\mathrm{lC}}=\delta\left(\frac{\mathrm{E}}{\mathrm{H}}\right)^{0.5}\left(\frac{\mathrm{P}}{\mathrm{c}^{3 / 2}}\right)
$$

where $\mathrm{E}\left(\mathrm{Nmm}^{-2}\right)$ is the elastic modulus of TiN/NbN coating evaluated in nanoindentation hardness measurement, $\mathrm{H}\left(\mathrm{Nmm}^{-2}\right)$ is the coating microhardness, $\mathrm{P}(\mathrm{N})$ is the applied normal load, and c $(\mathrm{mm})$ is the average radial crack length obtained from the indentation impression using a SEM.

Potentiodynamic polarisation method was utilised to study the corrosion performance of the coating and uncoated substrates. A computer controlled potentiostat (Gill-AC, ACM instruments, Grange-over-Sands, UK) was used for the corrosion current measurements. The sweeping potential was varied from $-1000 \mathrm{mV}$ to $+1000 \mathrm{mV}$ at the scan rate of $1 \mathrm{mV} / \mathrm{s}$ during the measurements. The tests were carried out in two different electrolytes, namely, a $3.5 \% \mathrm{NaCl}$ and artificial body fluid known as Hank's solution in order to replicate the environment in the human body. These tests were repeated twice for each electrolyte and each sample.

The metal ion release from TiN/NbN coated CoCrMo alloy samples in Hank's solution was studied by inductively coupled plasma mass spectrometry (ICP-MS) analysis. Hank's solution containing corrosion debris was diluted 1:100 with 1\% nitric acid before ICP-MS analysis on a Nexion 350-X ICP mass spectrometer (PerkinElmer, Waltham, MA, USA). Metal concentration was quantified against known standards using isotopes $\mathrm{Co}^{59}, \mathrm{Cr}^{52}$, $\mathrm{Mo}^{98}, \mathrm{Nb}^{93}$, and $\mathrm{Ti}^{47}$. Furthermore, a micro filter was placed before the syringe to make sure that no micro particles were present in the solution which might block the nebuliser. The composition of Hank's solution used for this research is shown in Table 1.

Table 1. Composition of Hank's solution.

\begin{tabular}{cc}
\hline Compound & Molecular Weight $(\mathrm{g} / \mathbf{m o l})$ \\
\hline $\mathrm{NaCl}$ & 58.44 \\
\hline $\mathrm{KCl}$ & 74.55 \\
\hline $\mathrm{CaCl}_{2}$ & 110.98 \\
\hline $\mathrm{MgSO}_{4} \cdot 7 \mathrm{H}_{2} \mathrm{O}$ & 246.47 \\
\hline $\mathrm{MgCl}_{2} \cdot 6 \mathrm{H}_{2} \mathrm{O}$ & 203.30 \\
\hline $\mathrm{Na}_{2} \mathrm{HPO}_{4} \cdot 2 \mathrm{H}_{2} \mathrm{O}$ & 177.99 \\
\hline
\end{tabular}

\section{Results and Discussion}

\subsection{Coating Microstructure}

Figure 1a shows the cross-section SEM images of $\mathrm{TiN} / \mathrm{NbN}$ superlattice coatings deposited on silicon wafers, whereas Figure $1 \mathrm{~b}$ shows the surface morphology of such coatings deposited on CoCrMo substrates. The coating exhibited an extremely dense columnar structure without any intercolumnar voids. The individual columns are wide and terminated with smooth column tops in contrast to coatings with dome shaped rough columns deposited under low ionisation conditions such as pure UBM. The surface morphology of the coatings (Figure 1b) also revealed that the column tops are indeed hemispherical and smooth with surface roughness of $R_{\mathrm{a}}=0.06 \mu \mathrm{m}$. These dense microstructures demonstrated the effect of increased metal ion bombardment due to HIPIMS discharge. During a reactive $\mathrm{Ar}+\mathrm{N}_{2}$ HIPIMS discharge on a metal target, more metal ions are generated, along with the dissociation of a high proportion of molecular nitrogen into $\mathrm{N}^{1+}$ atomic ions. OES studies of Ti and Cr HIPIMS discharge showed up to twofold ionised metal species in the dense plasma region of the magnetron [20]. Ti metal ion to Ti metal neutral ratio increased up to a factor of four during TiN deposition using combined HIPIMS/UBM technique as 
compared to conventional UBM sputtering [15]. Such metal ions arriving at the surface of the growing film during the deposition bear enough potential to diffuse through the open column boundaries formed by atomic shadowing effect, thereby eliminating porosity between individual columns, leading to dense coatings [15].

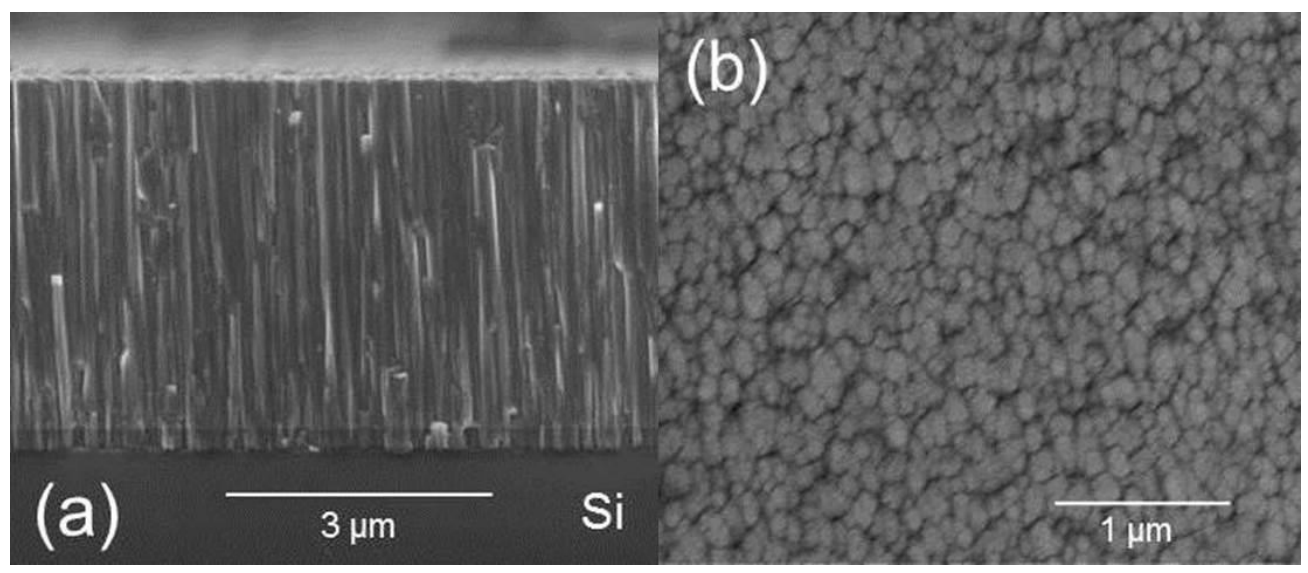

Figure 1. SEM images of TiN/NbN multilayer coating (a) Cross-section (Si substrate); (b) plan view (polished CoCrMo alloy substrate).

\subsection{Adhesion Strength of the Coatings}

Rockwell indentation and scratch tests were used to evaluate the adhesion strength of the TiN/NbN coatings deposited on soft CoCrMo substrate. Prior to the deposition of coatings, $\mathrm{Nb}^{+}$metal ion etching was carried out using HIPIMS discharge to improve the adhesion. For TiN/NbN coatings deposited on CoCrMo substrate, no cracking or any adhesive delamination of the coating was seen around the Rockwell indents (Figure 2a). This adhesion quality can be classified as Class 1 according to BS ISO 26443:2008. The scratch test results were analysed using an optical microscope to identify the critical normal force $\left(L_{\mathrm{C} 2}\right)$ at the start of failure events such as spallation. In the case of TiN/NbN coating, no spallation was observed in the described scratch test up to normal force of $L_{\mathrm{C} 2}=15 \mathrm{~N}$. The significance of this result can be understood when compared to scratch adhesion strength values of $107 \mathrm{mN}$ for TiN coatings deposited on Ar ion pre-treated CoCrMo samples reported as being sufficient [21]. It is very well understood that the load bearing capacity of a coating substrate system depends upon the substrate material properties. The coating failure at higher loads could be attributed to the large plastic deformation first initiated in the soft CoCrMo substrate near the coating substrate interface rather than the coating, eventually leading to the deformation of the coating resulting in crack initiation [22].

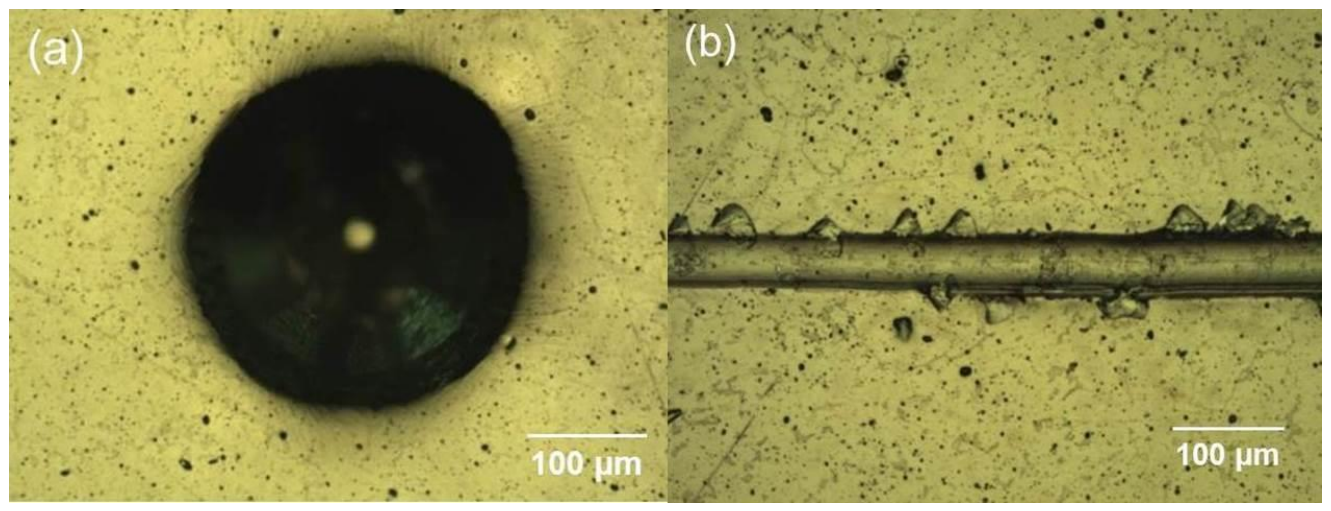

Figure 2. Optical micrographs of (a) Rockwell C indent; (b) scratch track produced to determine the adhesion strength of TiN/NbN nanoscale multilayer coating deposited on CoCrMo alloy. 


\subsection{Mechanical and Tribological Properties}

Table 2 summarises the data from the measurements of the mechanical and tribological properties for the TiN/NbN multilayer coating and bare CoCrMo alloy. Nanoindenter and Knoop microhardness testers were used to determine the hardness of the coatings and the $\mathrm{CoCrMo}$ substrate. For the nanoindentation measurements, the load was increased up to a maximum value of $20 \mathrm{mN}$ at the rate of $40 \mathrm{mN}$ per min and then decreased at the same rate to zero. The indentation depth was less than $1 / 10$ th of the coating thickness in order to avoid the influence of substrate on the hardness measurements. TiN/NbN multilayer coating exhibited high nano hardness value of $28 \mathrm{GPa}$. A similar procedure was followed to determine the hardness of the bare CoCrMo alloy, which was found to be as low as $6 \mathrm{GPa}$. The Knoop microhardness value of the multilayer coating and uncoated alloy were found to be $3100 \mathrm{HK}$ and $900 \mathrm{HK}$, respectively.

Table 2. Properties of CoCrMo substrate and $\mathrm{TiN} / \mathrm{NbN}$ multilayer coating.

\begin{tabular}{cccccc}
\hline Sample & $\begin{array}{c}\text { Thickness } \\
(\boldsymbol{\mu \mathbf { m } )}\end{array}$ & $\begin{array}{c}\text { Microhardness } \\
(\mathbf{H K})\end{array}$ & $\begin{array}{c}\text { Nanohardness } \\
(\mathbf{G P a})\end{array}$ & $\begin{array}{c}\text { Young's Modulus } \\
(\mathbf{G P a})\end{array}$ & $\begin{array}{c}\text { Bilayer Thickness } \\
(\mathbf{n m})\end{array}$ \\
\hline CoCrMo substrate & - & 900 & $6 \pm 1$ & 215 & - \\
\hline $\begin{array}{c}\text { TiN/NbN } \\
\text { multilayer coating }\end{array}$ & 4.2 & 3100 & $28 \pm 2$ & 390 & 3 \\
\hline
\end{tabular}

The pin on disc tests carried out on the bare substrate showed that the average coefficient of friction $(\mu)$ of the bare CoCrMo substrate was rather high at 0.83. SEM analysis (not shown) of the wear track revealed that under the test conditions, the CoCrMo alloy experienced severe plastic deformation. The wear mechanism in this case can be classified as a three-body abrasive wear mechanism. In contrast, the TiN/NbN multilayer coating showed lower coefficient of friction of 0.7 with smoother wear track free of deep grooves, delamination, and accumulation of wear debris (Figure 3). The values of the coefficient of friction for the uncoated and $\mathrm{TiN} / \mathrm{NbN}$ coated samples were taken from the steady state regime of the sliding test.

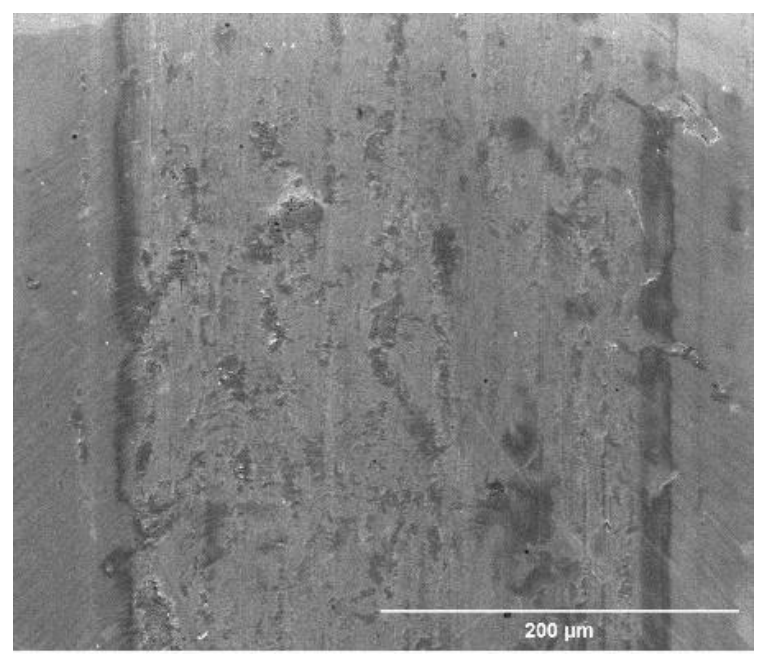

Figure 3. Plan view SEM image of the wear track generated on TiN/NbN coated alloy.

Owing to the high hardness, the TiN/NbN multilayer coating showed enhanced wear resistance with a wear coefficient $\left(K_{C}\right)$ as low as $1.4 \times 10^{-14} \mathrm{~m}^{3} \cdot \mathrm{N}^{-1} \cdot \mathrm{m}^{-1}$, which represents an improvement by a factor of two when compared to the wear resistance of the bare substrate $\left(K_{\mathrm{C}}=2.7 \times 10^{-14} \mathrm{~m}^{3} \cdot \mathrm{N}^{-1} \cdot \mathrm{m}^{-1}\right)$. 


\subsection{Fatigue Resistance}

The fatigue resistance of the coating was studied by applying repeated impact load using a CemeCon impact testing machine (CemeCon, Horseheads, NY, USA) in ambient conditions. Figure 4 shows the crater surface morphology of the uncoated specimen after 1 million impacts. The impact crater surface area can be separated into two distinct regions, namely, region 1, the area around the periphery of the crater, and region 2, the centre of the crater. Region 1 clearly depicts the build-up of impact wear debris moved away from the centre of the crater. The high magnification image of the crater revealed the formation of criss-cross shear bands near the periphery of the crater due to brittle fracture of the work hardened material. On the other hand, in region 2, the impact crater was found to be covered with compacted metal oxide debris as confirmed by EDX elemental mapping (Figure 5) and FIB-CS, smeared on to the surface of the base metal. The thickness of this compacted layer was measured to be between 0.5 and $0.7 \mu \mathrm{m}$. In this region, surprisingly no evidence of surface and subsurface cracks was found, despite the high number of impacts ( 1 million). Hence it can be stated that the main mechanism of the crater formation is plastic deformation with progressive surface oxidation due to transformation of the impact energy in localised heating and environmental attack.

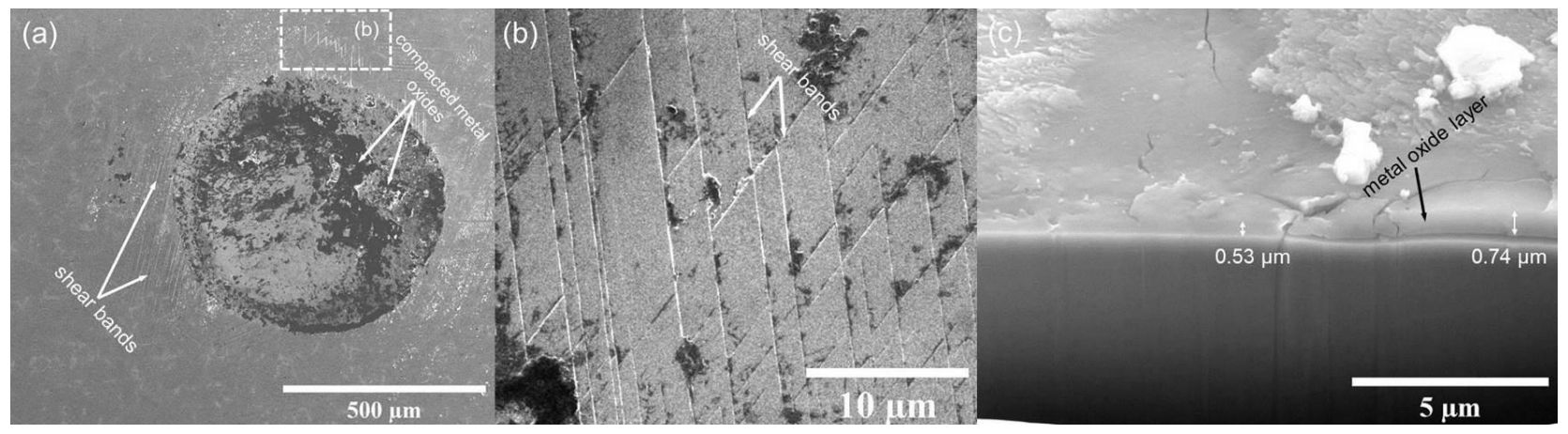

Figure 4. Plan view SEM images of uncoated CoCrMo alloy: (a) impact crater; (b) criss-cross shear bands near the periphery of the crater; (c) FIB cross-section of the compacted oxide layer at the centre of the crater.

\begin{tabular}{|c|c|c|c|c|c|c|c|}
\hline & $\mathrm{Ti}$ & $\mathrm{Cr}$ & $\mathrm{Nb}$ & $\mathrm{Co}$ & $\mathrm{Mo}$ & $\mathrm{O}$ & $\mathrm{N}$ \\
\hline $\begin{array}{c}\text { Uncoated CoCrMo } \\
\text { alloy }\end{array}$ & & & & & & & \\
\hline $\begin{array}{c}\text { TiN/NbN multilayer } \\
\text { coating }\end{array}$ & & & & & & & \\
\hline
\end{tabular}

Figure 5. EDX elemental mapping of the uncoated and TiN/NbN multilayer coated CoCrMo specimens.

The EDX analysis of impact crater of TiN/NbN superlattice coated specimen (Figure 5) showed that the degradation mechanism of the coating is similar to that of the base material which is oxidation behaviour. However, the surface damaged area is significantly restricted to the centre of the crater. It is evident from the presence of coating constituents such as $\mathrm{Ti}$, $\mathrm{Nb}$, and $\mathrm{N}$ along with oxygen inside the crater around the damaged area that the coating is still intact even after 1 million impacts.

Figure 6a shows plan-view SEM images of the impact crater created on TiN/NbN coating deposited on CoCrMo substrate after 1 million impacts at $500 \mathrm{~N}$ dynamic load. A Dektak profilometer was used to measure the dimensions of the crater. The depth and diameter of the crater were of about 21 and $675 \mu \mathrm{m}$, respectively. Figure $6 \mathrm{~b}, \mathrm{c}$ show FIBSEM cross-sections showing the microstructure beneath the impact crater of the TiN/NbN 
superlattice coating. The image of the coating-substrate interface area (Figure 6b) inside the impact crater revealed that part of the coating was still intact, even after a million impacts, which demonstrates the strong adhesion between the coating and substrate due to the metal ion etching [12] used prior to the deposition and high toughness of the TiN/NbN multilayer coating.

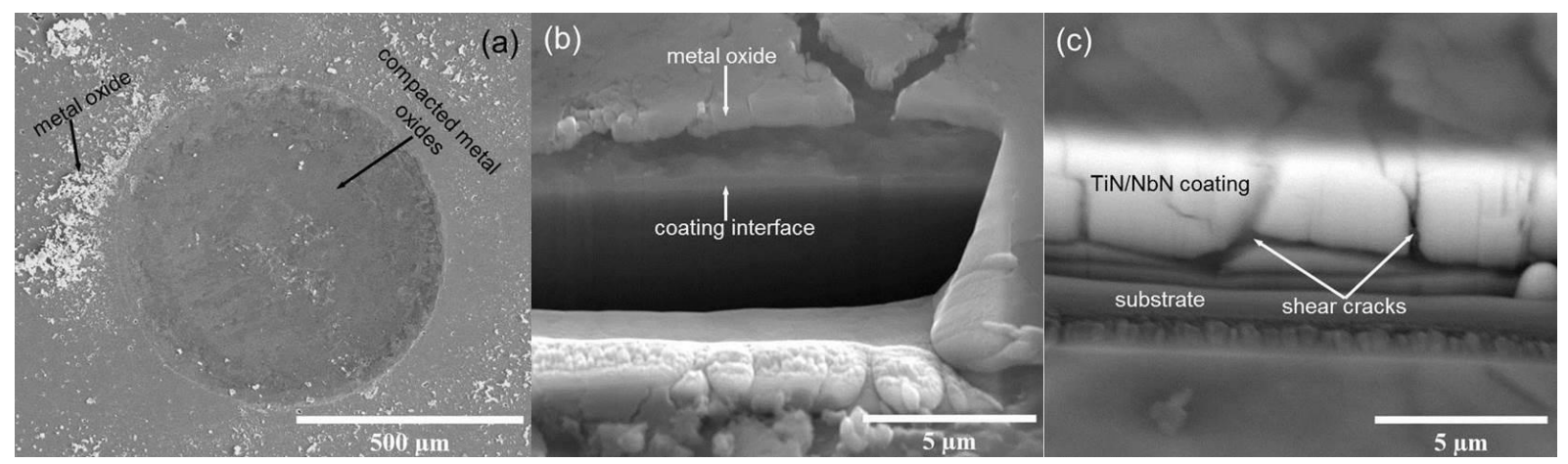

Figure 6. SEM images of TiN/NbN coating: (a) impact crater; (b) FIB cross-section showing coating surface interface; (c) FIB cross-section of the coating near the periphery of the crater.

The cross-section in Figure $6 \mathrm{c}$ reveals that the maximum damage in the form of several cracks generated in the region away from the centre of the crater where the applied load was not normal to the surface and has a shear component as well. However, it is important to note that the cracks did not propagate directly from the surface to the coating substrate interface but tend to deflect in a lateral direction, thus demonstrating the very well documented role of the interfaces between the individual nanolayers as sites for elastic energy dissipation and crack deflection [17], which is a major advantage of the nanoscale multilayer coating architecture.

\subsection{Fracture Toughness}

One important mechanical property which needs to be evaluated for metal alloys used in metal-on-metal implant applications is the fracture toughness, $K_{\text {Ic }}$. The $K_{\text {Ic }}$ value of the material represents the ability of the material to resist edge crack formation under high loading conditions, which are typical for this application. Moreover, the combination of high hardness, TiN/NbN coating $(H=28 \mathrm{GPa})$ deposited on a soft CoCrMo substrate $(H=6 \mathrm{GPa})$ imposes further demands on the harder material due to the lack of load bearing capacity of the softer material. Hence, the fracture toughness of the coating becomes of paramount importance for the performance and the lifetime of such composite material systems. In this work, $K_{\text {Ic }}$ value for both the uncoated specimen and the superlattice coating were calculated using modified fracture toughness method, which uses a pyramidal indenter such as a Vickers indenter to penetrate the surface and potentially initiate cracks along the edges of the indent produced in the tested material. For all experiments, a constant defined normal load of $30 \mathrm{kgf}$ was applied. The tests were repeated at least two times to confirm the repeatability of $K_{\mathrm{Ic}}$ value.

Figure $7 \mathrm{a}-\mathrm{c}$ depicts the surface morphology of the Vickers indentation impression formed on the uncoated CoCrMo alloy imaged at different magnifications. It can be seen from Figure $7 \mathrm{a}-\mathrm{c}$ that the edges and corners of the square indent were crack-free. However, the higher magnification image (Figure 7c) revealed the formation of a limited number of shear bands around and within the faces of the indent due to the significant plastic deformation experienced by the alloy during the indentation test. As expected, a high $K_{\text {Ic }}$ value of $312.3 \mathrm{MPamm}^{1 / 2}$ was calculated from the softer high plasticity CoCrMo substrate material, whereas the $K_{\mathrm{Ic}}$ value was much lower at $112.5 \mathrm{MPamm}^{1 / 2}$ for the ceramic superlattice $\mathrm{TiN} / \mathrm{NbN}$ coating material. However, compared to other ceramic coatings 
such as $\mathrm{TiN}$, this value was significantly higher, thus demonstrating the enhanced fracture toughness of nanoscale multilayer structured $\mathrm{TiN} / \mathrm{NbN}$ coating [19].

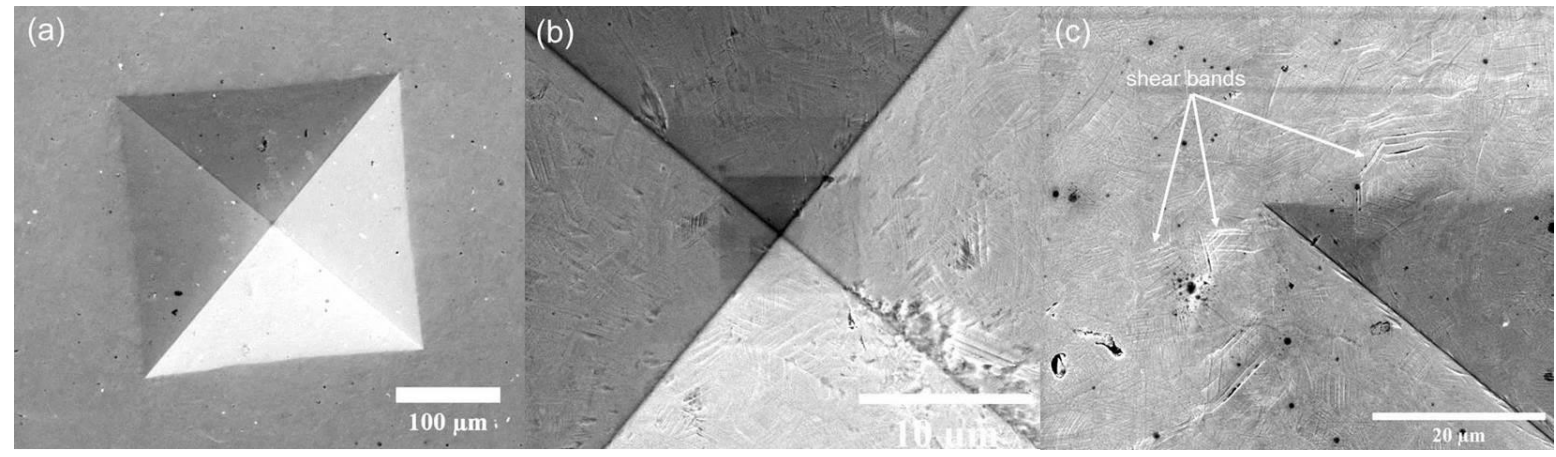

Figure 7. Plan view SEM images of uncoated CoCrMo alloy: (a) Vicker's indent impression; (b) high magnification image of the centre of the indent; (c) one of the edges of the square impression.

Figure 8a-c illustrates the indent impressions on the specimen coated with TiN/NbN multilayer coating. No evidence of radial cracks along the edges of the indent was found, but Palmqvist type cracks were detected. The origin of these cracks was within the faces of the indent and moving towards edges and corners of the impression. Few of these cracks were found to be larger ( $>115 \mu \mathrm{m}$ in length from the edge of the indent) than expected and were spread everywhere across the indent impression (Figure 8a,c). On the other hand, a high density of tensile cracks was noticed within the faces of the indent. Broad cracks found at the centre of the indent (Figure $8 \mathrm{~b}$ ) indicated the fracture of the columns of the coating. Higher magnification image of the same area showed that the columns were pressed during the loading, which led to complete damage of the area and the formation of tensile cracks. Further analysis showed that these tensile cracks originated through flow of tensile stress formed at the interface of the coating and substrate [23].

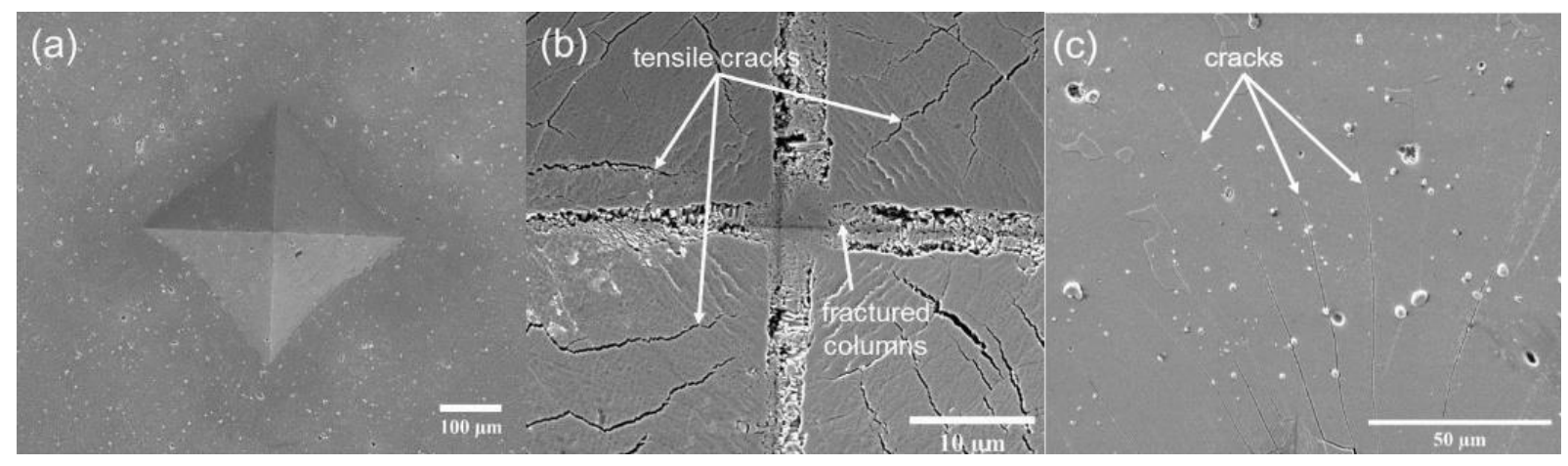

Figure 8. SEM plan view images of TiN/NbN coated specimen: (a) Vickers indent impression; (b) high-resolution image of the centre of the indent; $(\mathbf{c})$ one of the edges of the square impression.

\subsection{Corrosion Properties}

Potentiodynamic polarisation method was used to study the corrosion behaviour of the TiN/ $\mathrm{NbN}$ multilayer coating and bare CoCrMo substrate material in $3.5 \% \mathrm{NaCl}$ and Hank's solution. The corrosion curves are given in Figure 9. As expected, the bare CoCrMo substrate showed low corrosion potential and high corrosion currents as compared to the coated sample. The $E_{\mathrm{corr}}$ value of the uncoated substrate tested in $\mathrm{NaCl}$ and Hank's solution were found to be about -533 and $-750 \mathrm{mV}$, respectively. The corrosion potential ( $\left.E_{\mathrm{corr}}\right)$ of the TiN/ $\mathrm{NbN}$ coated CoCrMo alloy tested in Hank's solution increased to $-470 \mathrm{mV}$ and further increased to $-365 \mathrm{mV}$ when tested in $3.5 \% \mathrm{NaCl}$ electrolyte. This increase in the 
$E_{\text {corr }}$ value suggested that the coating acted as a reliable corrosion barrier to the underlying CoCrMo substrate.

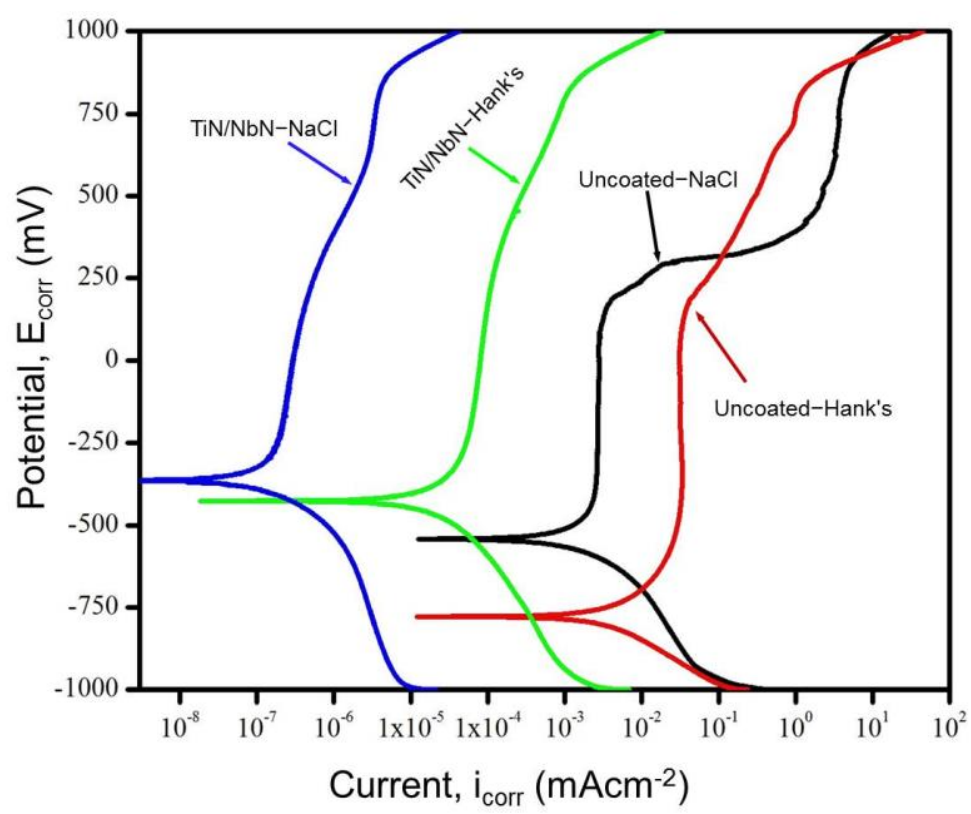

Figure 9. Potentiodynamic polarisation curves of CoCrMo substrate and $\mathrm{TiN} / \mathrm{NbN}$ multilayer coating in various test electrolytes.

All samples exhibited excellent passivation behaviour and high pitting potentials, irrespective of the corrosion electrolyte. However, the $\mathrm{TiN} / \mathrm{NbN}$ coated samples showed consistently lower corrosion current densities in both test electrolytes as compared to the uncoated CoCrMo alloy. In Hank's solution, the corrosion current density reduction was three orders of magnitude, whereas it was four orders of magnitude lower as compared to the bare $\mathrm{CoCrMo}$ alloy when using the $3.5 \% \mathrm{NaCl}$ electrolyte. The corrosion current is a good indicator of the corrosion rate, i.e., the rate of oxidation and reduction reactions taking place on the specimen surface. Typically, the corrosion rate is proportional to the corrosion current. Hence, lower corrosion currents represent slow corrosion reactions. Therefore, it is evident from the low corrosion currents recorded for TiN/NbN multilayer coatings that these coatings provide excellent corrosion protection to the CoCrMo substrate. This superior corrosion resistance can be attributed to two reasons, namely, the formation of a highly protective passive surface layer and effective hindering of the electrolyte penetration due to the excellent coating density achieved by the HIPIMS deposition.

\subsection{Inductively Coupled Plasma Mass Spectrometry (ICPMS)}

The average concentration of metal ions released (in parts per billion) in simulated body fluid (Hank's solution) during potentiodynamic polarisation tests was monitored by ICPMS. For the case of uncoated CoCrMo alloy after the corrosion test in Hank's solution, the ICPMS showed that the $\mathrm{Co}$ and $\mathrm{Cr}$ metal ions were present in high concentration (Table 3). Surprisingly, no trace of Mo metal ions was detected for the uncoated specimen. Importantly, it can be noted that the TiN/ $\mathrm{NbN}$ nanoscale multilayer coating significantly reduced the release of the harmful ions, namely, $\mathrm{Co}$ (carcinogenic, heavy metal ions) from the CoCrMo substrate material. The $\mathrm{Co}, \mathrm{Cr}$, and $\mathrm{Mo}$ ion discharge levels from the test samples coated with nanostructured $\mathrm{TiN} / \mathrm{NbN}$ were found to be well below the detection limit of the analysis technique used (Table 3). 
Table 3. Average concentration of various metal ions in parts per billion.

\begin{tabular}{cccccc}
\hline Sample & Co & $\mathbf{C r}$ & $\mathbf{M o}$ & $\mathbf{N b}$ & $\mathbf{T i}$ \\
\hline Uncoated CoCrMo substrate & 0.26 & 0.18 & 0 & 0 & 0 \\
\hline TiN/NbN multilayer coating & 0 & 0 & 0 & 0.53 & 0.14 \\
\hline
\end{tabular}

The analysis also revealed the presence of $\mathrm{Nb}$ and Ti ions originating from the coating material. However, such ions are considered as harmless due to the high biocompatibility of both $\mathrm{Ti}$ and $\mathrm{Nb}$. Enhancing the wear resistance of the coating as shown in Section 3.3 played a defining role in minimising the amount of the wear debris released during the wear process, which is seen as an important approach in minimising the amount of the metal ions released in the body.

\section{Conclusions}

- $\quad \mathrm{TiN} / \mathrm{NbN}$ multilayer coatings were deposited on CoCrMo alloys by utilising mixed HIPIMS/UBM sputtering. Scratch tests revealed superior coating to substrate adhesion due to the HIPIMS etching prior to coating deposition. Scanning electron microscopy analysis showed that these coatings are extremely dense without any intercolumnar voids.

- Nanoindentation measurements showed enhanced coating hardness of $28 \mathrm{GPa}$ as compared to $6 \mathrm{GPa}$ of the uncoated alloy. Dry sliding pin on disc tests against the alumina ball showed enhanced tribological properties of the multilayer coating. The friction coefficient $(\mu)$ of 0.7 and wear coefficient $\left(K_{\mathrm{C}}\right)$ of $1.4 \times 10^{-14} \mathrm{~m}^{3} \cdot \mathrm{N}^{-1} \cdot \mathrm{m}^{-1}$ of the multilayer coating were significantly lower as compared to that of the bare material with $\mu$ of 0.83 and $K_{C}$ of $2.7 \times 10^{-14} \mathrm{~m}^{3} \cdot \mathrm{N}^{-1} \cdot \mathrm{m}^{-1}$.

- Detailed EDX analysis together with FIB cross-section investigation of the impact crater generated on coated alloy revealed that that the degradation mechanism of the coating was similar to that of the base material which is oxidation behaviour, and the coating was still intact inside the crater around the damaged area even after 1 million impacts, confirming the excellent coating to substrate bonding strength.

- Fatigue analysis of the coated alloy showed that the columns of the coating were pressed during the loading which led to complete damage of the area and the formation of tensile cracks which originated through flow of tensile stress formed at the interface of the coating and substrate.

- Potentiodynamic polarisation tests in $\mathrm{NaCl}$ and Hank's solutions revealed the clear passivation behaviour, several orders of magnitude lower corrosion currents, and high pitting potentials of the coating, which guarantee excellent protection to the base alloy in such aggressive environments.

- Inductively coupled plasma mass spectrometry analysis of the coated sample corroded in Hank's solution revealed that the leaching of harmful metal ions from the base material was reduced to below the detection limit of the technique, thus demonstrating the high barrier properties of the coating.

Author Contributions: A.A.S.: experimental work, formal analysis, investigation, validation of results and preparation of manuscript draft; Y.P.: experimental work; K.S.: investigation, validation of results and preparation of manuscript draft; I.K.: identifying the demand and application field; A.E.: leading the HIPIMS research; P.H.: conceptualisation, supervision, validation of results, preparation and reviewing of manuscript draft. All authors have read and agreed to the published version of the manuscript.

Funding: This work was supported by Zimmer-Biomet UK Limited.

Institutional Review Board Statement: Not applicable.

Informed Consent Statement: Not applicable. 
Data Availability Statement: The data presented in this study are available on request from the corresponding author. The data are not publicly available due to issues related to the proprietary rights.

Acknowledgments: The authors would like to thank Gary Robinson is for his technical assistance.

Conflicts of Interest: The authors declare no conflict of interest.

\section{References}

1. Okazaki, Y.; Gotoh, E. Comparison of metal release from various metallic biomaterials in vitro. Biomaterials 2005. [CrossRef] [PubMed]

2. Wapner, K.L. Implications of metallic corrosion in total knee arthroplasty. Clin. Orthop. Relat. Res. 1991, 271, 12-20. [CrossRef]

3. McGregor, D.B.; Baan, R.A.; Partensky, C.; Rice, J.M.; Wilbourn, J.D. Evaluation of the carcinogenic risks to humans associated with surgical implants and other foreign bodies-A report of an IARC Monographs Programme Meeting. Eur. J. Cancer 2000, 36, 307-313. [CrossRef]

4. Wisbey, A.; Gregson, P.J.; Tuke, M. Application of PVD TiN coating to Co-Cr-Mo based surgical implants. Biomaterials 1987, 8. [CrossRef]

5. Pham, V.H.; Yook, S.W.; Lee, E.J.; Li, Y.; Jeon, G.; Lee, J.J.; Kim, H.E.; Koh, Y.H. Deposition of TiN films on Co-Cr for improving mechanical properties and biocompatibility using reactive DC sputtering. J. Mater. Sci. Mater. Med. 2011. [CrossRef] [PubMed]

6. Harman, M.K.; Banks, S.A.; Andrew Hodge, W. Wear analysis of a retrieved hip implant with titanium nitride coating. J. Arthroplast. 1997. [CrossRef]

7. Neumann, H.G.; Beck, U.; Drawe, M.; Steinbach, J. Multilayer systems for corrosion protection of stainless steel implants. Surf. Coat. Technol. 1998. [CrossRef]

8. Hamelynck, K.J.; Woering, R.G. Ceramic Surface Engineered Metal-on-Metal Hips System for Total Hip Arthroplasty and Resurfacing Hip Arthroplasty. ACCIS White Pap. 2009. Available online: https://silo.tips/download/ceramic-surfaceengineered-metal-on-metal-hips-system-for-total-hip-arthroplasty (accessed on 14 April 2021).

9. Hovsepian, P.E.; Ehiasarian, A.P.; Purandare, Y.; Sugumaran, A.A.; Marriott, T.; Khan, I. Development of superlattice CrN/NbN coatings for joint replacements deposited by high power impulse magnetron sputtering. J. Mater. Sci. Mater. Med. 2016, 27, 1-10. [CrossRef] [PubMed]

10. Ehiasarian, A.P. Fundamentals and Applications of HIPIMS. In Plasma Surface Engineering Research and Its Practical Applications; Wei, R., Ed.; Research Signpost: Kerala, India, 2007; ISBN 978-81-308-0257-2.

11. Ehiasarian, A.P.; Vetushka, A.; Gonzalvo, Y.A.; Sáfrán, G.; Székely, L.; Barna, P.B. Influence of high power impulse magnetron sputtering plasma ionization on the microstructure of TiN thin films. J. Appl. Phys. 2011, 109, 104314. [CrossRef]

12. Ehiasarian, A.P.; Wen, J.G.; Petrov, I. Interface microstructure engineering by high power impulse magnetron sputtering for the enhancement of adhesion. J. Appl. Phys. 2007. [CrossRef]

13. Ehiasarian, A.; Hovsepian, P.; Munz, W. Combined Coating Process Comprising Magnetic Field-Assisted, High Power, Pulsed Cathode Sputtering and an Unbalanced Magnetron. U.S. Patent 7,081,186, 25 July 2006.

14. Reinhard, C.; Ehiasarian, A.P.; Hovsepian, P.E. CrN/NbN superlattice structured coatings with enhanced corrosion resistance achieved by high power impulse magnetron sputtering interface pre-treatment. Thin Solid Film. 2007, 515, 3685-3692. [CrossRef]

15. Hovsepian, P.E.; Sugumaran, A.A.; Purandare, Y.; Loch, D.A.L.; Ehiasarian, A.P. Effect of the degree of high power impulse magnetron sputtering utilisation on the structure and properties of TiN films. Thin Solid Film. 2014, 562. [CrossRef]

16. Hovsepian, P.E.; Ehiasarian, A.P. Six strategies to produce application tailored nanoscale multilayer structured PVD coatings by conventional and high power impulse magnetron sputtering (HIPIMS). Thin Solid Film. 2019, 688. [CrossRef]

17. Hovsepian, P.E.; Münz, W.-D. Synthesis, Structure, and Applications of Nanoscale Multilayer/Superlattice Structured PVD Coatings. In Nanostructured Coatings; Cavaleiro, A., De Hosson, J.T.M., Eds.; Springer: New York, NY, USA, 2006; pp. 555-644. ISBN 978-0-387-48756-4.

18. Ehiasarian, A.P.; Tietema, R.; Bugyi, R.; Klimczak, A.; Hovsepian, P.E.; Doerwald, D. A Vacuum Treatment Apparatus, a Bias Power Supply and a Method of Operating a Vacuum Treatment Apparatus. U.S. Patent 20,100,025,230 A1, 4 February 2010.

19. Zhang, S.; Sun, D.; Fu, Y.; Du, H. Toughness measurement of thin films: A critical review. Surf. Coat. Technol. 2005, 198. [CrossRef]

20. Ehiasarian, A.P.; New, R.; Münz, W.D.; Hultman, L.; Helmersson, U.; Kouznetsov, V. Influence of high power densities on the composition of pulsed magnetron plasmas. Vacuum 2002. [CrossRef]

21. Türkan, U.; Öztürk, O.; Eroğlu, A.E. Metal ion release from TiN coated CoCrMo orthopedic implant material. Surf. Coat. Technol. 2006, 200, 5020-5027. [CrossRef]

22. Bell, T.; Dong, H.; Sun, Y. Realising the potential of duplex surface engineering. Tribol. Int. 1998, 31, 127-137. [CrossRef]

23. Fu, K.; Chang, L.; Zheng, B.; Tang, Y.; Yin, Y. Analysis on cracking in hard thin films on a soft substrate under Berkovich indentation. Vacuum 2015, 112. [CrossRef] 